\title{
Correction to: Comparing self-assessment of laparoscopic technical skills with expert opinion for gynecological surgeons in an operative setting
}

Rami Kilani ${ }^{1 *}$ and Wesam Aleyadeh²

\section{Correction to: Gynecol Surg}

https://doi.org/10.1186/s10397-018-1048-2

In the publication of this article [1], the contributing author Wesam Aleyadeh was missing. This has now been updated in this correction.

\section{Author details}

${ }^{1}$ Hashemite University, Zarqa, Jordan. ${ }^{2}$ Ministry of Health, Amman, Jordan.

Received: 17 March 2019 Accepted: 17 March 2019

Published online: 27 May 2019

\section{Reference}

1. Kilani R, Aleyadeh W (2018) Comparing self-assessment of laparoscopic

technical skills with expert opinion for gynecological surgeons in an operative setting. Gynecol Surg 15:16 https:/doi.org/10.1186/s10397-018-1048-2

*Correspondence: rkilani2000@yahoo.com

The original article can be found online at https://doi.org/10.1186/s10397018-1048-2

${ }^{1}$ Hashemite University, Zarqa, Jordan

Full list of author information is available at the end of the article 